\title{
Allophony and Allomorphy Cue Phonological Acquisition: Evidence from the European Portuguese vowel system*
}

\author{
Paula Fikkert \\ Radboud University Nijmegen \\ p.fikkert@let.ru.nl \\ Maria João Freitas \\ University of Lisbon/Onset-CEL \\ joaofreitas@fl.ul.pt
}

\begin{abstract}
The acquisition of morphophonological alternations is hardly investigated in phonology (Macken 1995, Bernhardt \& Stemberger 1998, Hayes 2004, Kerkhoff 2004). Learnability models of phonological alternations often assume that allophonic variation is easy to learn, as it usually follows from the phonology of the language (Peperkamp \& Dupoux 2002, Hayes 2004). On the other hand, these models assume that allomorphic variation is acquired late and learners often show paradigm uniformity at the early stages of development. In our study of longitudinal data of seven European Portuguese children, aged between $0 ; 11$ and 3;7, we investigate the acquisition vowel alternations and show that children start acquiring those very early. In particular, children even seem to distinguish vowels in neutralized context to a large extent. We argue that children acquire the abstract phonological vowel system of European Portuguese very early, precisely because of the large amount of systematic variation in the input. We will provide empirical evidence for the claim that the phonological processes in the language help children to set up the abstract vowel system of European Portuguese.
\end{abstract}

Key words: vowel alternations, acquisition, allophony, European Portuguese.

\section{Table of Contents}

Introduction

1. The European Portuguese vowel system

2. The acquisition problem: hypotheses and predictions

3. The database
4. The acquisition of allophonic variation in European Portuguese vowels
5. Discussion
6. Conclusions

References

* We would like to thank the audiences of the Toronto Contrast workshop (2002), the IASCL conference in Madison (2002) and Going Romance in Nijmegen (2003), and we especially thank Elan Dresher, Aditi Lahiri, Conxita Lleó, Claartje Levelt, Raquel Santos, Leo Wetzels, Tania Zamuner, and two anonymous reviewers. Paula Fikkert would like to thank NWO for funding the research project «Changing Lexical Representations in the Mental Lexicon». The database used is developed at the Laboratório de Psicolinguística, Universidade de Lisboa. The research of Maria João Freitas was supported by FCT/FEDER.POCTI/33277/LIN/2003. 


\section{Introduction}

Research investigating the acquisition of phonology has mainly focused on the relationship between the targeted adult forms ('input') and the children's own production of those forms ('output'). This is usually expressed in terms of the children's developing phonological system. In the old days, this was done by means of child-specific processes, such as fronting, consonant harmony, etc. (e.g. Ingram 1974, Smith 1973, Kiparsky \& Menn 1977, and many others). Nowadays, the relationship between the targeted input and the realized output forms is usually expressed in an OT-framework. On the assumption that in the initial state of the child's phonological grammar markedness constraints outrank faithfulness constraints (Smolensky 1996, Tesar \& Smolensky 1998, 2000), children have more highly ranked markedness constraints in their grammars than adults, because children have not yet demoted all relevant markedness constraints below the relevant faithfulness constraints. In other words, child language is typically less marked than the corresponding adult language (see Kager, Pater \& Zonneveld 2004, and many references therein). The standard assumption is that input structures are represented in an adultlike fashion, and that any systematic discrepancies between the input and a child's output are due to the immature phonological system of the child. Yet, there is a growing body of literature suggesting that children's early lexical representations may not be adult-like yet, and if they are, children are not always able to use the details in representations for perception and/or production (see for instance, Fennell 2004, Swingley 2005, Fikkert, to appear). It is therefore worth investigating how phonological representations are built up during the acquisition process and what kind of evidence children may use to do so.

In the literature on acquisition of phonology there is little work done on the acquisition of phonological 'rules' that also play a role in the adult system; i.e., allophonic and allomorphic variation, even though this has always been the hallmark in adult phonology, which often sets out to determine which contrasts are important in the language under investigation and what underlying phonological representations look like. In fact, the issue of lexical representations is seldom discussed in the literature on the acquisition of phonology.

An exception is Kiparsky \& Menn (1977)' model of acquisition, which tries to incorporate the development of lexical representations and the acquisition of adult phonological rules. They argue that during acquisition children have two types of rules: invented rules to simplify the adult target forms in such a way that they can be produced by the children (the child-specific processes), and a set of learned rules, which correspond to the rules in adult phonology. Kiparsky \& Menn present the model sketched in figure 1. In this model, children start out assuming that the words they hear are represented in such as way that they are fairly similar to the acoustic signal. That is, children do not yet have underlying representations that are distinct from the perceived acoustic phonetic representations. Children try to imitate these words. However, since perfect imitation is beyond children's capacities they invent rules to simplify the adult target forms. Each child may come up with his or her own set of sometimes fairly idiosyncratic rules. 
A. Underlying representations hypothesized by the child

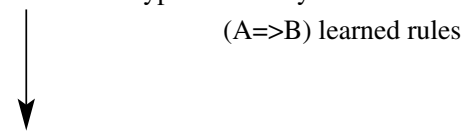

B. Phonetic representations perceived by the child

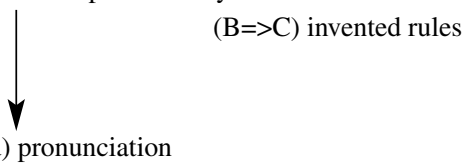

Figure 1. Kiparsky \& Menn's (1977) model of phonological acquisition.

In the course of development, children's articulation and processing skills will improve and they do therefore not rely as heavily on these invented rules as before. That is, the invented rules start to disappear. At the same time, children are acquiring the adult phonology (the to-be-learned rules). As a consequence, children are learning that underlying representations are more abstract than the perceived phonetic representations. Consequently, a second level of representation appears: abstract phonological representations. In other words, while the difference between phonetic representations and production forms becomes smaller (and ultimately disappears), the abstract phonological representation becomes more distinct from the phonetic representations. ${ }^{1}$ Moreover, while the set of invented rules is decreasing (and ultimately disappears), the set of learned rules is increasing. This set of rules largely refers to allophonic variation and morphophonological alternations. Yet, this latter component is not worked out in any detail, and neither is it picked up in the subsequent literature on acquisition of phonology (e.g. Macken 1995, Bernhardt \& Stemberger 1998, Peperkamp \& Dupoux 2002, Hayes 2004). What is attractive about the model is that it provides a way to account for developing lexical representations, which are related to the acquisition of the target phonological system.

Therefore, we claim that the acquisition of allophonic and allomorphic variation (the learned rules) should be central to the theory of acquisition as well, as it provides evidence for the way children store phonological representations and for their system of phonological contrasts. Yet, we are unaware of studies that discuss acquisition data on these issues.

The fact that acquisition of morphophonological alternations is hardly studied is partly due to the fact that most acquisition studies are based on Germanic languages, in which morphophonological alternations only play a limited role. In most cases allomorphic variation can be straightforwardly accounted for as a consequence of the

1. It remains an undetermined issue whether the detailed phonetic representation with which the child started the acquisition process remains part of the stored mental lexicon next to the abstract phonological representation, or is replaced by the latter. 
general phonotactics of the language, the classical example being the choice of allomorph selection in English plural formation (Albright \& Hayes 2003, Hayes 2004). Cases in which the base word shows variation have not been investigated in detail (but see Kerkhoff 2004, and Zamuner et al. 2006). An example comes from Dutch plural formation, where the singular of the word hond is pronounced with a final [t], due to final devoicing, but the plural honden with a [d], giving rise to variation of the base form: hon[t] - hon[d]en 'dog sg.-pl.'). Studies on the acquisition of Romance languages with a rich system of morphophonological variation are important, as they will shed light on the matter of how children acquire a phonological system with a substantial amount of systematic surface variation.

In is important to distinguish between allophonic variation, for which a number of researchers have argued that this can be acquired on the basis of the general phonotactics of the languages, and allomorphic variation, which is more difficult to acquire as this requires children to link various variants to specific morphological conditions. Many cases of allomorphy cannot be learned without lexical knowledge, i.e. morphology and semantics (Peperkamp \& Dupoux 2002). In general, children at early stages of acquisition seem to ignore allomorphy and adhere to the principle of Paradigm Uniformity. In Dutch, for example, children often produce the plural of hond [hont] as [hontə(n)] (Kager 1999, Kerkhoff 2004). Stated in terms of Optimality Theory, Hayes (2004) assumes that output-to-output faithfulness is initially (i.e. in the initial state) ranked very high, ruling out allomorphy and supporting paradigm uniformity. Thus, in general, it is assumed that morphophonology is acquired late, and that children are not able to deal with variation to construct underlying lexical representations in early stages of phonological acquisition.

The situation is even more difficult if there is also neutralization at stake. Contrasts that are neutralized are often hard to learn (Peperkamp \& Dupoux 2002). To illustrate this, let us briefly look at the case of vowel alternations in Chamorro, presented in Peperkamp \& Dupoux (2002), as this shows similarities to the European Portuguese vowel system, although it is a bit less complex. In this language /u/ and $\mathrm{lo} /$ are reduced to $[\mathrm{U}]$ in unstressed position, as shown in (1):

\section{(1) Chamorro vowel reduction}

$$
\begin{aligned}
& \text { [dágu] } \sim \text { [i dəgú-kù] 'yam - my yam' } \\
& \text { [pécu] } \sim \text { [i pıcó-kù] ' 'chest - my chest' }
\end{aligned}
$$

Since $[U]$ only occurs in unstressed position, and $/ \mathrm{u} /$ and $/ \mathrm{o} /$ in stressed position, it is not difficult to infer the rule of vowel reduction. However, it is impossible, given $[U]$ to infer the underlying vowel. Peperkamp and Dupoux (2002) predict that «in the phonological representation of words in the mental lexicon, infants will include $[v]$ rather than the underlying full vowel from which it is derived. As morphology becomes available, they can recode the words more abstractly and delete $[u]$ from the phonological representation.» In other words, they argue, like Kiparsky \& Menn (1977), that phonological representations can change in the course of development. 
In many languages - Chamorro and European Portuguese being among them the interaction between phonology and morphology gives rise to many alternating forms, which may constitute a challenge for the child: how are variant forms related, and which phonological representations must be stored in the mental lexicon. As most of these alternations are very regular and predictable, traditional accounts have assumed one underlying form from which related forms are derived. If children follow the same logic they can be called 'little linguists'. Although this approach is currently under attack - in the exemplar-based models storage of all variants is often assumed (Bybee 2001, and others) - it seems highly plausible that at least one route to arrive at the variant forms is through the acquisition of phonological processes (the learned rules in Kiparsky \& Menn's model), which may lead to storage of adult-like abstract underlying representations.

In this paper, we report on how children deal with the variation they encounter in the target language, as reflected in their own production forms. We will argue that young children do not necessarily store all target forms as they hear them, but that they are able to deduce information about underlying representations from alternations they encounter in the input. The fact that European Portuguese has a number of processes that give rise to various kinds of vowel alternations cues children to focus on contrastive features in the phonological system. Here we will focus on one type of vowel alternation in particular: allophonic variation (see Fikkert 2005 for an account on stress-dependent variation in adult European Portuguese). To account for the attested patterns, we also consider stress-related vowel reduction. Our goal here is to investigate how the complex interaction of allophonic variation and neutralization in the vowel system of European Portuguese (henceforth EP) can be acquired. In the next section, we will first sketch the EP target system that children need to acquire. Subsequently, we will define the exact learning problem in section 2. Section 3 presents the database on which our analysis is based. Section 4 gives the analyses of the acquisition data. In section 5 the results are discussed. The final section summarizes the main conclusions.

\section{The European Portuguese vowel system}

European Portuguese has eight oral vowels in surface stressed positions, and four in unstressed position as sketched in (2), based on Mateus \& d'Andrade (2000) and Fikkert (2005). Although [e] does appear as a stressed vowel on the surface, its appearance in this context is very restricted and predictable, as we will show below. For that reason, Mateus \& d'Andrade do not assume it to be an underlying vowel, but consider it derived. Fikkert (2005) presents an analysis of the EP vowel systems, assuming that vowels can be [labial], [dorsal] or [coronal]; moreover, there are two Tongue Height dimensions: [low] and [high]. We further assume here that [coronal] is the default Place of Articulation (see also Mateus \& d'Andrade 2000). ${ }^{2}$

2. For detailed arguments for these assumptions see Fikkert (2005). We further argue there that /i/ and $/ \mathrm{u} /$ must be specified for [high], and that the low vowels $[\mathrm{a}, \rho, \varepsilon]$ are specified for [RTR]. 
(2) Stressed position

\begin{tabular}{c|cccc}
\multicolumn{1}{c}{ high } & \multicolumn{1}{c}{ i } & & $\mathrm{u}$ \\
\hline \multirow{3}{*}{ low } & & $\mathrm{e}$ & $\mathrm{e}$ & $\mathrm{o}$ \\
\cline { 2 - 5 } & RTR & $\varepsilon$ & $\mathrm{a}$ & $\mathrm{J}$ \\
& & cor & dors & lab
\end{tabular}

Unstressed position

$\begin{array}{ccc}\text { high } & \text { i } & \\ & \text { u } & \text { e }\end{array}$

cor dors lab

The system exhibits vowel reduction in unstressed position very systematically, as shown in (3a). The high vowels /i/ and /u/ do not show alternation, as shown in $(3 b)$.

(3) Vowel alternations in stressed vs. unstressed position

\begin{tabular}{|c|c|c|c|}
\hline $\begin{array}{l}\text { 'm[a]la } \\
\text { 's[c]la } \\
\text { 'm[e]do } \\
\text { 'm[o]da } \\
\text { '1[o]bo }\end{array}$ & $\begin{array}{l}\text { 'bag' } \\
\text { 'saddle' } \\
\text { 'fear' } \\
\text { 'fashion' } \\
\text { 'wolf' }\end{array}$ & $\begin{array}{l}\mathrm{m}[\mathrm{e}] \text { 'linha } \\
\mathrm{s}[\mathrm{i}] \text { 'lar } \\
\mathrm{m}[\mathrm{i}] \text { 'dinho } \\
\mathrm{m}[\mathrm{u}] \text { 'dista } \\
\text { l[u]'binho }\end{array}$ & $\begin{array}{l}\text { 'bag' diminutive } \\
\text { 'to saddle' } \\
\text { 'fear' diminutive } \\
\text { 'dressmaker' } \\
\text { 'wolf' diminutive }\end{array}$ \\
\hline $\begin{array}{l}\text { '1[i]vro } \\
\text { t[[u]bo }\end{array}$ & $\begin{array}{l}\text { 'book' } \\
\text { 'tube' }\end{array}$ & $\begin{array}{l}\text { 1[i]'vrinho } \\
\text { t[u]'binho }\end{array}$ & 'tube' diminutive \\
\hline
\end{tabular}

From a traditional generative view of phonology, it is assumed that the stressed vowels are underlying, and the unstressed ones derived. From the stressed vowels the unstressed ones can easily be derived (as the relationship is 'many-to-one'), as shown in (4), but the reverse is not true, as is shown in (5), where stressed vowels cannot be inferred from unstressed vowels (a one-to-many case, as in Chamorro):

(4) Reduction of stressed vowels ('many-to-one')
a. /a/ reduces to $[\mathrm{e}]$
b. $/ \varepsilon, e /$ reduce to $[\mathrm{i}]$
c. $/ \mathrm{o}, \mathrm{o} /$ reduce to $[\mathrm{u}]$
d. /i, u/ are not affected by the general vowel reduction rule

(5) Unstressed vowels relate to stressed vowels in a 'one-to-many' fashion
a. [e] corresponds to /a/
b. [i] corresponds to $/ \varepsilon$, e/
c. $[\mathrm{u}]$ corresponds to $/ \mathrm{o}, \mathrm{o}, \mathrm{u} /$
d. [i] corresponds to /i/

Fikkert (2005) argues that this vowel reduction process can be accounted for by assuming that vowels lose the Tongue Height feature [low] in unstressed position 


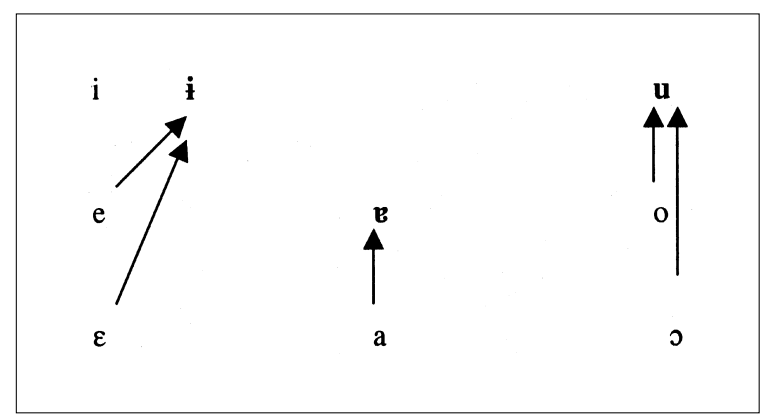

Figure 2. Vowel reduction in unstressed position.

(see also Wetzels 1995). As /i/ and /u/ are specified for [high], they do not undergo change. All other vowels reduce in unstressed position, as depicted in Figure 2.

We therefore argue that $[\mathrm{i}]$ must be a coronal vowel without Tongue Height specification, i.e. the default vowel (see also Freitas 2004 for further arguments for this position). We further argue that $[\mathrm{u}]$ has two different underlying representations: underlying $/ \mathrm{u} /$ is a high labial vowel, whereas unstressed $/ \mathrm{u} /$ deriving from underlying $/ \mathrm{o} / \mathrm{or} / \mathrm{J} /$ is a labial vowel without Tongue Height features (neither [high] nor [low]).

Of special interest to us is the vowel $[\mathfrak{e}]$. Whereas $[\mathfrak{b}]$ mostly occurs in unstressed position (as the result of the vowel reduction process just mentioned), it can also surface in stressed position in the two conditions given in (6) with examples in (7):

(6) Conditions in which stressed [e] appears

a. stressed $/ \mathrm{a} / \rightarrow[\mathrm{e}]$ if it is followed by a nasal consonant

b. stressed /e/ $\rightarrow[\mathrm{e}]$ if it is followed by a palatal segment

(7) a. Stressed underlying /a/ $\rightarrow[\mathrm{e}] / \_$Nasal consonant

$\begin{array}{llll}\text { a'r/an/a } & \rightarrow & \text { a'r[en]a } & \text { 'spider' } \\ \text { 'c/an/a } & \rightarrow & \text { 'c[en]a } & \text { 'cane' } \\ \text { 'c/am/a } & \rightarrow & \text { 'c[em]a } & \text { 'bed' }\end{array}$

b. Stressed underlying /e/ $\rightarrow[\mathrm{e}] /$ _Palatal segment (nasal, liquid, fricative or glide)

\begin{tabular}{|c|c|c|c|}
\hline de's/ep/os & $\rightarrow$ & dés[en]os & 'drawings' \\
\hline$a^{\prime} b / e \Lambda / a$ & $\rightarrow$ & $\mathrm{a}^{\prime} \mathrm{b}[\mathrm{e} \Lambda] \mathrm{a}$ & 'bee' \\
\hline bo'ch/e $\int / a s$ & & bo'ch[e $\left.\int\right]$ as & 'cheeks' \\
\hline cerv/ez/a & & cerv[e3]a & 'beer' \\
\hline '1/ej/ & $\rightarrow$ & '1[ej] & 'law' \\
\hline
\end{tabular}

Thus, underlying /a/ and /e/ have two different surface forms, depending on the nature of the following consonant, a typical case of allophonic variation. Stressed 
/a/ can occur as either [a] or [e]; stressed /e/ can occur as [e] or [e]. As the occurrence of $[\mathrm{e}]$ is entirely predictable - given the stressed vowel inventory - current analyses (e.g. Mateus 1975; d'Andrade 1977; Mateus \& d'Andrade 2000) have assumed that stressed $[\mathrm{e}]$ is not part of the inventory of phonological vowels in the language, but assume it to be derived from either /a/ or /e/ (7a, b). Moreover, the corresponding unstressed vowels in the diminutive forms, given in (8a, b) differ for the forms in $(7 a, b)$, due to the process of vowel reduction depicted in Figure 2.

a. Underlying /a/

$\begin{array}{llll}\text { ar[ }[\mathrm{e}] \mathrm{nha} & \text { 'spider' } & \operatorname{ar}[\mathrm{e}] \text { 'nhinha } & \text { 'spider' diminutive } \\ \text { 'c[e]na } & \text { 'cane' } & \mathrm{c}[\mathrm{e}] \text { 'ninha } & \text { 'can' diminutive } \\ \text { 'c[e]ma } & \text { 'bed' } & \mathrm{c}[\mathrm{e}] \text { 'minha } & \text { 'bed' diminutive }\end{array}$

b. Underlying /e/



Therefore, the main synchronic argument to postulate different underlying vowels for $(7 a, b)$ comes from the morphologically related forms in which the vowels undergo reduction in unstressed position. The underlying vowel /a/ in (7a) systematically remains $[\mathrm{e}]$ in $(8 \mathrm{a})$, whereas the underlying vowel in (7b) systematically reduces to $[\mathrm{i}]$, as in $(8 \mathrm{~b})$. [ $[\mathrm{e}]$ is the unstressed counterpart of /a/, while [i] is the unstressed counterpart of /e/ or / $/ \varepsilon$. This analysis finds support in the fact that in some dialects /a/ surfaces as [a] and /e/ as [e], though this is not the case in the dialect spoken in Lisbon, which is the dialect of the children in this study.

EP also has diphthongs that are traditionally analyzed as underlying /e/ followed by a palatal glide. As the underlying /e/ occurs in a palatal environment, the vowel surfaces as $[\mathrm{b}]$ in $(9 \mathrm{a})$. Other Vowel-Glide sequences never undergo vowel reduction, as shown in the second column of (9a) and in (9b).

(9) a. Underlying /e/ plus palatal glide

$\begin{array}{llll}\text { 'qu[ej]jo } & \text { 'cheese' } & \text { qu[ej]'jinho } & \text { 'cheese' diminutive } \\ \text { 'r[ej] } & \text { 'king' } & \text { r[pj]'nado } & \text { 'kingdom' } \\ \text { 'p[pj]xe } & \text { 'fish' } & \text { p[rj]'xinho } & \text { 'fish' diminutive } \\ \text { 'I[pj]te } & \text { 'milk' } & 1[\mathrm{pj}] \text { tinho } & \text { 'milk' diminutive }\end{array}$

b. No reduction in vowel-glide sequences

$\mathrm{p}$ [aw]'sado 'slowly'

c[aj]'xinha 'box' diminutive

pn[ew]monia 'pneumonia'

Finally, in EP a stressed vowel followed by a palatal fricative may optionally diphthongize. That is, forms with and without the glide [j] are in free variation, as 
shown in (10). This is evidence that the palatal consonants have a feature [high], which characterizes $/ \mathrm{i} /$ and $/ \mathrm{j} /$.

(10) Palatal fricative may cause diphthongization of preceding vowel

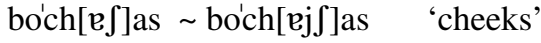
cerv[ez]a $\sim \operatorname{cer} v[$ [ej3]a 'beer'

\section{The acquisition problem: hypotheses and predictions}

As has become clear from the description of the EP vowel system, a child acquiring EP will encounter many stress-dependent vowel alternations, where stressed vowels retain their Place of Articulation features, but lose the Tongue Height feature [low] in unstressed position. From earlier work (Freitas 2004, and Fikkert 2005) we know that children make very few mistakes with respect to the Place of Articulation features of vowels: coronal vowels are always realized as coronal, labial vowels as labial, and dorsal vowels as dorsal. Tongue Height features are more difficult to acquire, as we will see below.

Our primary interest in this paper is how children deal with allophonic variation, in particular, how they produce target stressed /e/ and /a/, which have alternating forms, depending on the segmental environment they occur in (allophony). Target underlying /a/ remains dorsal in all allophonic and allomorphic contexts. However, target underlying /e/ is coronal in most contexts, but appears as dorsal [ $\mathrm{e}]$ before palatals if stressed. To complicate matters, in the environment before a palatal nasal, the contrast between stressed underlying /a/ and /e/ is neutralized: both surface as stressed $[\mathrm{e}]$. Thus, there is both allophonic and allomorphic variation, as well as neutralization in the context of a palatal nasal, as in the words in (11):

(11) a. $\operatorname{ar}[\mathrm{en}] \mathrm{a}$

b. de's[ej]os 'spider'

'drawings' underlying /a/

underlying /e/

This raises the question of when and how children acquire such a complicated vowel system. There are several possible answers.

We could entertain the 'Little Linguist Hypothesis'. If children are little linguists, they might want to start with the stressed vowel system and derive the unstressed vowels from the stressed ones, as in that case they are dealing with a many-to-one situation, shown in (4). The reverse situation is much more difficult. In a 'one-to-many' situation errors are likely to arise, as shown in (5). Combined with the fact that children seem to pay attention to stress (e.g. Echols \& Newport 1992, Gerken 1996, Fikkert 1994, and others), and acquire vowel reduction fairly late (e.g. Levelt 2002, Fikkert 1994, Freitas 2004, and others), it seems a reasonable hypothesis to assume that children focus on stressed vowels first, and subsequently pay attention to the unstressed ones. Under this hypothesis, we expect children to produce the stressed counterparts for unstressed vowels, until the reduction rule is acquired. Moreover, a further prediction is that children start with a vowel system with eight stressed vowels, including $/ \mathrm{e} /$. 
The question then is, how and when do children learn the real nature of the stressed vowel $[\mathrm{e}]$. They must learn to make use of implicit negative evidence: stressed [a] never occurs before nasals, and stressed [e] never appears before palatals. If children are able to use implicit negative evidence, or stated differently, use statistical regularities in the input, they may discover the dual nature of stressed [e]. However, given the fact that the stressed vowels /a/ and /e/ neutralize before a palatal nasal the child cannot solely rely on the distribution of stressed vowels to arrive at adult-like lexical representations. To distinguish the stressed vowels in (11a) and (11b), children must be able to compare different paradigmatic forms, as shown in (12). It seems that the only way to learn that the vowels preceding the palatal nasal in aranha and desenhos are underlyingly different in nature is by learning morphologically related pairs:
a. $\operatorname{ar}[\mathrm{e}] \mathrm{nh}]+\mathrm{a}$
‘spider' dim
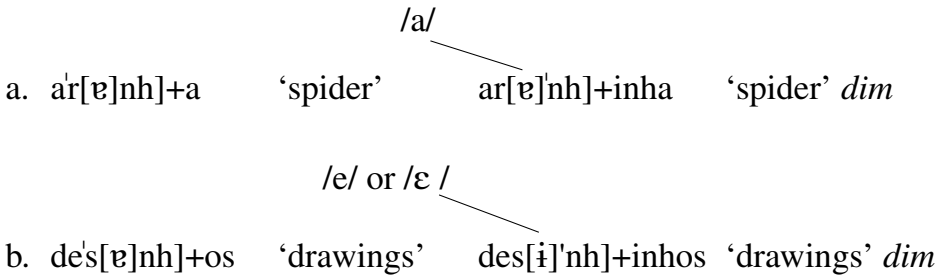

To summarize, under the 'little linguist' hypothesis, we may expect that children start with the stressed vowel system. At first, errors may involve the production of unstressed vowels without vowel reduction. As vowel reduction is a very common process, it is presumably learned before allophonic variation, which must be acquired before allomorphic variation (needed to acquire the underlying contrast in the neutralizing context.)

In learnability accounts, such as Tesar \& Smolensky (1998, 2000), Hayes (2004), and Peperkamp et al. (in press), often the following assumptions (or rather hypotheses) are made. First, prelexical children - children in their first year of life when they do not yet have a mental lexicon - have been shown to detect allophonic variation, presumably based on the distribution of segments in the target language (for instance, Jusczyk et al. 1999). If EP children can do the same, we predict that they can learn that surface $[\mathrm{e}]$ in the context of a right-adjacent nasal corresponds to an underlying /a/ and, similarly, that surface [ $\mathrm{e}$ ] in the context of a right-adjacent palatal corresponds to an underlying /e/ (allophonic variation). As prelexical infants already know the distributional regularities of the language, systematic errors in production are not predicted unless they are due to general articulatory problems. Children should also be able to learn that vowels are realized differently in stressed and unstressed position (stress-related vowel variation), as this can also largely be acquired on the basis of distributional patterns in the language, except for the relationship between stressed [ $\mathrm{e}]$ and unstressed [i], which is not straightforward, and may cause problems. Similarly, the neutralizing context is hard to acquire, as in this context, the child crucially has to make use of allomorphic variation, which is acquired late. 
A third alternative is that children simply store what they perceive and hence, store variant forms of words, i.e. storage is exemplar-based (e.g., Bybee 2001). Under this assumption one might expect that there are no systematic errors in production of target vowels; alternatively, errors are frequency-based. In particular, in the neutralizing context, we predict that children realize both underlying /e/ and underlying $/ \mathrm{a} /$ as $[\mathrm{e}]$. As children never hear these target vowels produced differently in that context, they should treat both underlying vowels the same and realize both vowels as [e]. That is, they arrive at the stressed vowel system in (2a), including the [e].

The different theories make different predictions with respect to the expected errors: under the 'little linguist' hypothesis, the main error type would be that unstressed vowels have the same segmental structure as the stressed vowels, until the reduction rule is acquired. In the learnability account, errors may be expected in the neutralizing context only, as this cannot be learned solely on the basis of distributional regularities in the input. Finally, under an exemplar theory no systematic errors are predicted, as words are stored correctly, and there is no need for deriving abstract underlying representations. If errors occur, these must be related to frequency of those forms in the input. It seems that under all predictions, children are expected to have difficulties acquiring the underlying contrast between stressed /e/ and /a/ in the neutralizing context of a right-adjacent palatal nasal. If children show a difference in behavior with regard to the forms in (12), this difference must be due to the fact that children have been able to compare morphologically related forms. It turns out that the children indeed are treating both vowels differently. Before we turn to the acquisition data, we first introduce the database on which this research is based.

\section{The database}

Our study is based on longitudinal spontaneous data from 7 monolingual children acquiring European Portuguese spoken in Lisbon. At the start of a one-year period of data collection the age of the children varied between 10 months and 2 years and 7 months. The children were videotaped once a month at the children's homes during spontaneous interaction with the principal investigator (the second author). Sessions lasted between 30 and 60 minutes. The data are phonetically transcribed and entered into the $4^{\text {th }}$ Dimension program 'Wordbase', which was developed at the Max Planck Institute for Psycholinguistics in Nijmegen. The database contains a total of 18654 utterances.

Although the data have been collected longitudinally, in the paper we have collapsed the data of each child for the main analyses. We extracted all children's productions of target words with stressed /a/ followed by a nasal (section 4.1), and of target words with stressed /e/ followed by a palatal consonant (section 4.2). We compared the children's productions of stressed /e/ and /a/ before a palatal nasal, i.e. the context where both neutralize (section 4.3). Subsequently, we considered the same environments in unstressed position (section 4.4). A summary of the results is found in section 4.5. The number of data for each child is fairly limited and often no development could be detected. However, where we are able to report on developmental changes, we will do so. 


\section{The acquisition of allophonic variation in European Portuguese vowels}

\subsection{Acquisition of allophonic variation of stressed vowel /a/}

Stressed target /a/ can surface as either [a] or [e], depending on the segmental context, as discussed in section 2. In (13), we present a representative sample of children's productions of target words with stressed underlying /a/ before nasal consonants, which in the adult language surfaces as [e].

(13) Children's production data of target stressed /a/ $\rightarrow[\mathrm{e}] /$

\begin{tabular}{|c|c|c|c|c|}
\hline 'ch[em]a & 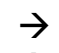 & {$\left[\int e\right]$} & (Marta $1 ; 2.0)$ & 'to call' $3^{\text {rd }} s g$ \\
\hline 'c[em]a & 2 & ['keme] & (Inês $1 ; 9.19$ ) & 'bed' \\
\hline 'c[en]a & $\rightarrow$ & ['ka] & (Luís 1;9.29) & 'stick' \\
\hline c $[\mathrm{em}] \mathrm{a}$ & $\rightarrow$ & {$[\mathrm{ke} \beta \mathrm{e}]$} & (Raquel $1 ; 10.2$ ) & 'bed' \\
\hline ba'n[en]a & $\rightarrow$ & [ménene] & (Inês $1 ; 10.29$ ) & 'banana' \\
\hline 'v[em]os & $\rightarrow$ & ['Emuf] & (Marta $1 ; 11.10)$ & 'to go' $1^{s t} p l$ \\
\hline [en]o & $\rightarrow$ & [ibienu] & (Marta $2 ; 0.26)$ & 'piano' \\
\hline ic $[\mathrm{en}] \mathrm{o}$ & $\rightarrow$ & ['ka] & (João 2;3.19) & 'pelican' \\
\hline en]o & $\rightarrow$ & ['ba] & (Inês $1 ; 5.11$ ) & 'shower' \\
\hline en]o & $\rightarrow$ & ['baju]/ ['bejnu] & (Inês $1 ; 9.19$ ) & 'shower' \\
\hline $\operatorname{tr}[\mathrm{en}] \mathrm{a}$ & & {$\left[\int^{\prime}\right.$ tene $]$} & (Marta $1 ; 10.4$ ) & 'strange' \\
\hline
\end{tabular}

From the data in (13) it is clear that stressed underlying /a/ surfaces as either [a] or [e] in the children's production data. This can clearly be seen in Figure 3, which gives the percentages of occurrence of production forms for target stressed /a/ in nasal context for all children. The raw total numbers of children's productions of stressed /a/ before nasals is 261. Not all children show variation: some children almost invariable realize /a/ as [e]; One child, Inês, often uses [a], but does

/a/+Nasal in stressed position

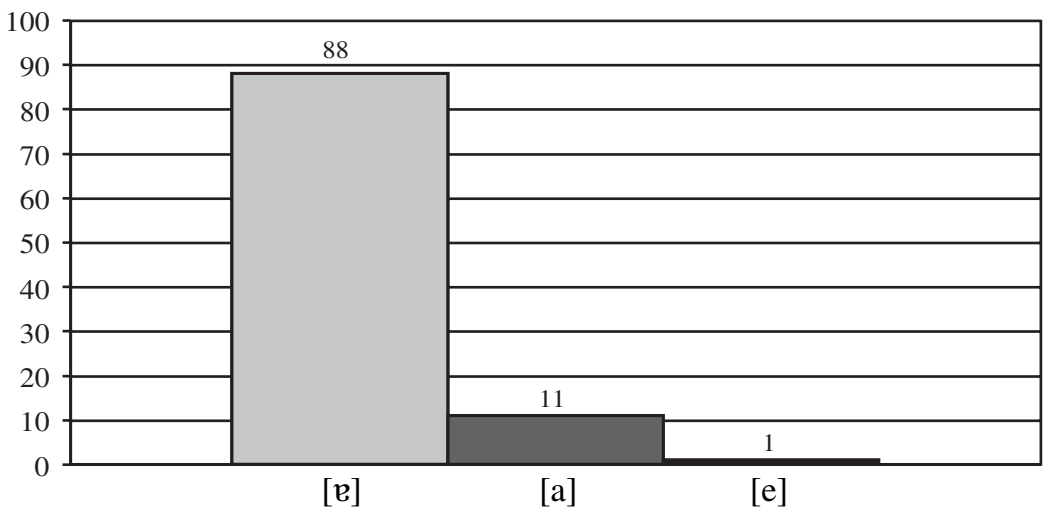

Figure 3. Percentage of different realizations for stressed /a/ followed by nasal. 
not realize the nasal in that case. In general, variation decreases in the course of development.

Stressed /a/ in non-nasal context always surfaces as a dorsal vowel [a], as shown by the examples in (14):

(14) Stressed /a/ in non-nasal context

\begin{tabular}{|c|c|c|c|c|}
\hline \multicolumn{2}{|l|}{ Adult form } & \multicolumn{2}{|c|}{ Child's production } & \\
\hline mác[a]co & $\rightarrow$ & ['kaw] & (Marta 1;3.8) & 'monkey' \\
\hline sap[a]to & $\rightarrow$ & [patu] & (Marta 1;3.8) & 'shoe' \\
\hline $\operatorname{col}[\mathrm{a}] \mathrm{r}$ & $\rightarrow$ & [ke'lale] & (Marta 1;5.17) & 'necklace' \\
\hline gir[a]fa & $\rightarrow$ & ['ga] & (Inês $1 ; 6.6$ ) & 'giraffe' \\
\hline bo'l[a]cha & $\rightarrow$ & ['lase] & (Luís 1;9.29) & 'cookie' \\
\hline $\mathrm{t}[\mathrm{a}] \mathrm{pa}$ & $\rightarrow$ & ['tape] & (Raquel 1;10.2) & 'to cover' imp. \\
\hline 's[a]po & $\rightarrow$ & ['`apu] & (Luís 1;11.20) & 'frog' \\
\hline a]po & $\rightarrow$ & ['apu]/ ['apo] & (João 2;2.28) & 'frog' \\
\hline a]lo & $\rightarrow$ & ['kaw] & (Laura 2;2.30) & 'cock' \\
\hline $\mathrm{a}[\mathrm{a}] \mathrm{r}$ & $\rightarrow$ & ['man] & (Pedro 2;7.0) & 'monkey' \\
\hline
\end{tabular}

In this context, there is no variation. Hence, the fact that children produce underlying /a/ differently if followed by a nasal than when followed by a non-nasal, indicates that children have some knowledge about the allophonic context.

\subsection{Acquisition of allophonic variation of stressed vowel /e/}

In (15) we present examples of children's production forms of target stressed underlying /e/ which surfaces as [e] before palatal consonants in the target language.

(15) Children's production data of target stressed /e/ $\rightarrow[\mathrm{e}] / \ldots$ Palatal consonant

\begin{tabular}{|c|c|c|c|c|}
\hline$[\mathrm{e} \Lambda]$ as & 7 & ['ge] & (Inês $1 ; 5.11$ ) & 'ears' \\
\hline$a^{\prime} b[\mathrm{e} \Lambda] \mathrm{a}$ & $\rightarrow$ & [ébele] & (Marta 1;7.18) & 'bee' \\
\hline $\mathrm{f}\left[\mathrm{e} \int\right] \mathrm{a}$ & $\rightarrow$ & [fe $\left.\int \mathrm{e}\right]$ & (Marta 1;8.18) & 'to close' $3^{\text {rd }} s g$ \\
\hline orr $[\mathrm{e} \Lambda]$ as & $\rightarrow$ & [wo:'leles] & (Inês $1 ; 10.29$ ) & 'ears' \\
\hline 'm[ej]a & $\rightarrow$ & ['mej]/['mej] & (Marta 2;0.26) & 'sock' \\
\hline $\mathrm{p}\left[\mathrm{pj} \int\right] \mathrm{e}$ & $\rightarrow$ & ['pej]/['pej] & (João 2;1.23) & 'fish' \\
\hline 's[pj]s & $\rightarrow$ & 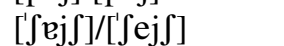 & (Luís 2;2.27) & 'six' \\
\hline verm $[\mathrm{e} \Lambda] \mathrm{o}$ & $\rightarrow$ & {$\left[v^{\prime} m e K u\right] /\left[v^{\prime} m \varepsilon \Lambda u\right]$} & (Laura $2 ; 2.30)$ & 'red' \\
\hline$\left.e \int\right] \mathrm{a} a$ & $\rightarrow$ & ['fejfa] & (Raquel 2;3.3) & 'to close the' $3^{r d}$ \\
\hline $\operatorname{rm}[\mathrm{e} \Lambda] \mathrm{o}$ & $\rightarrow$ & [vímpju]/[vìmeju] & (João $2 ; 8.27$ ) & 'red' \\
\hline ej]xa(-me) & . & 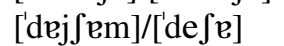 & (Pedro $3 ; 2.0$ ) & 'to let' $3^{\text {rd }} \mathrm{sg}$ \\
\hline 's[en]o & & ['zвnu] & (Marta 1;11.10) & 'drawing' \\
\hline en]o (a) & & ['tenu]/['tene] & (Luís 2;8.16) & 'to have' $1^{s t} s g$ \\
\hline
\end{tabular}

Figure 4 shows that underlying /e/ is produced either as [e] or as [e] or [e]. Children vary in their favorite choice: some children produce mostly dorsal vowels; others, like Inêz, prefer coronal vowels. Here the decrease in variation is not 


\section{/e/+Palatal in stressed position}

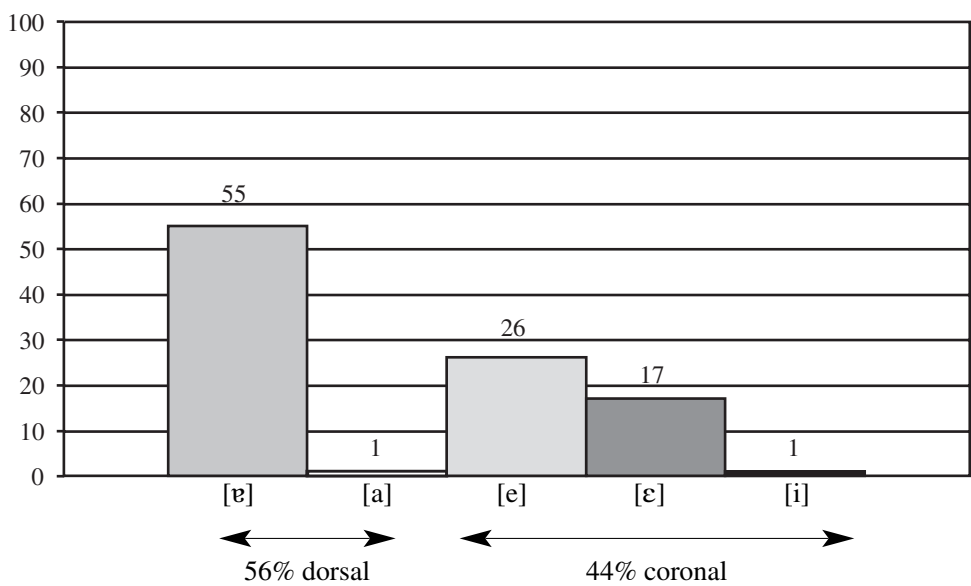

Figure 4. Percentage of different realizations for stressed /e/ followed by palatal.

clear at all; it rather looks like variation is increasing with development. We will come back to developmental trends later. The raw total numbers of children's productions of stressed /e/ before palatals is 210 .

To rule out the possibility that /e/ simply shows much variability in general, we also examined positions in which they should surface unchanged. In (16) examples are presented of underlying /e/ in stressed position in other contexts than before a palatal consonant. These data show that children's productions are invariably realized with a coronal vowel, although some errors occur with respect to vowel height. The forms never show up with a dorsal vowel.

(16) Stressed /e/ in non-palatal contexts

Adult form

In[e]s

cab[e]lo

ca'b[e]lo

'z[e]bra

pr[e]ta

'd[e]do

'm[e]sa

$\operatorname{tr}[\mathrm{e}] \mathrm{s}$

'v[e]rde

com[e]r

'v[e]rde

'P[e]dro

fáz[e]r

$\operatorname{tr}[\mathrm{e}] \mathrm{s}$
Child's production

$\begin{array}{ll}\rightarrow & \text { [ne'ne] } \\ \rightarrow & {[\text { kebew] }} \\ \rightarrow & \text { ['bew] } \\ \rightarrow & \text { ['cbe] } \\ \rightarrow & \text { ['pete]/['pite] } \\ \rightarrow & \text { ['dedu] } \\ \rightarrow & \text { ['meze] } \\ \rightarrow & \left.\text { [ti're } \int\right] \\ \rightarrow & \text { ['be] } \\ \rightarrow & {[\text { ku'me] }} \\ \rightarrow & \text { ['vedi] } \\ \rightarrow & \text { ['peðu] } \\ \rightarrow & {[\text { veze] }} \\ \rightarrow & \text { ['te } \theta]\end{array}$

(Inês $1 ; 0.25$ )

Name

(Marta 1;6.23)

'hair'

(Luís 1;9.29)

'hair'

(Luís 1;9.29)

'zebra'

(Inês 1;10.29)

'black'

(Raquel 1;11.20) 'finger'

(Laura 2;2.30)

'table'

(Laura 2;2.30)

'three'

(João 2;4.30)

'green'

(Pedro 2;7.0)

'to eat'

(Pedro 2;7.0)

'green'

(Pedro 2;7.0)

Name

(Pedro 2;8.19)

'to do'

(Raquel 2;10.8) 'three' 
The fact that /e/ in a palatal context shows considerably more variation than in a non-palatal context suggests that children possess knowledge of allophonic variation. Allophonic variation is thus acquired fairly early.

However, if we compare Figure 3 and 4, differences between the two allophonic contexts become clear. Although in these contexts the target language invariable has [e], the figures and examples in (14)-(16) show that children produce more variation with target underlying /e/, than with target underlying /a/. Moreover, children clearly distinguish underlying /a/ from underlying /e/. Underlying /a/ is invariably produced as dorsal, but underlying /e/ can either be dorsal or coronal. In nonneutralizing contexts /a/ and /e/ both are produced with the correct place of articulation. Stressed /a/ is correctly realized as [a] and stressed /e/ as a coronal vowel, i.e. mostly [e], but sometimes [e] or [i]. Before we discuss these results in more detail, let us first look at one context in particular: How do children treat underlying /a/ and /e/ before palatal nasals?

\subsection{The acquisition of stressed underlying /a/ and /e/ in a neutralizing context}

As shown in (11), before a palatal nasal underlying /a/ and /e/ in stressed position are completely neutralized. The data in (17) show that in this context, children still treat underlying /a/ and /e/ differently. Underlying /a/ surfaces as [a] or [e] (17a), underlying /e/ surfaces as, [e] or [e] (17b):

(17) Children's production data of target stressed /a/ and /e/ $\rightarrow[\mathrm{e}] /$ Palatal nasal

a. Target stressed /a/ $\rightarrow[\mathrm{e}] /$ _ Palatal nasal Adult form

\begin{tabular}{|c|c|c|}
\hline b[en]o & $\rightarrow$ & ['ba] \\
\hline 'b[en]o & $\rightarrow$ & ['baju]/ ['bejnu] \\
\hline es'tr[ej]a & $\rightarrow$ & ['Jtene] \\
\hline b[en]o & $\rightarrow$ & ['be] \\
\hline estr[ej]o & $\rightarrow$ & ['Stenu] \\
\hline b[вр]о & $\rightarrow$ & ['pej//nju] \\
\hline Esp[en]a & $\rightarrow$ & ['peje] \\
\hline cast[ej]a & 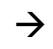 & [kef'tejne] \\
\hline
\end{tabular}

(Inês 1;5.11)

(Inês 1;9.19)

(Marta $1 ; 10.4$ )

(João 2;2.28)

(Laura 2;3.2)

(Luís 2;4.4)

(João $2 ; 6.11)$

(Pedro 2;8.19)

$$
\begin{aligned}
& \text { 'shower' } \\
& \text { 'shower' } \\
& \text { 'strange' } \\
& \text { 'shower' } \\
& \text { 'strange' } \\
& \text { 'shower' } \\
& \text { 'Spain' } \\
& \text { 'chestnut' }
\end{aligned}
$$

\begin{tabular}{|c|c|c|c|c|}
\hline \multicolumn{2}{|c|}{ Adult form } & \multicolumn{2}{|c|}{ Child's production } & \\
\hline de's[ej] & $\rightarrow$ & ['3ерии] & (Marta $1 ; 11.10)$ & 'drawing' \\
\hline (a) & $\rightarrow$ & ['tenu]/['teje] & $(\mathrm{Lu}$ & $e^{\prime} 1^{s t}$ \\
\hline 1]o & $\rightarrow$ & ['3enì] & $(\mathrm{Pe}$ & 'dra \\
\hline & $\rightarrow$ & ['tenu]/['teju] & (Laura 2;1 & ave' $l^{s t} s g$ \\
\hline & $\rightarrow$ & ['vene] & (Pedro $3 ; 2.25)$ & 'to come' imp. \\
\hline 1$] 0$ &  & ['tenì] & (Pedro 3;3.18) & 'to have' $1^{s t}$ \\
\hline
\end{tabular}

b. Target stressed /e/ $\rightarrow[\mathrm{e}] /$ _ Palatal nasal

Target /aj/ in stressed position is usually produced as an /a/-like, i.e. dorsal vowel [e] or [a], namely in $96 \%$ of the cases, while target /ej/ is produced as an 
/a/-like vowel ([e] or [a]) in $70 \%$ of the cases, and as an /e/-like vowel - mostly [e] - in 30\% of the cases. Although the numbers are very small, the data seem to suggest that children indeed treat both underlying vowels differently, at least in 30\% of the case, despite the fact that they are neutralized in stressed position. The question is how children know that some surface vowels before palatal nasals correspond to target /a/ and others to target /e/? The difference between the two vowels shows up when they appear in unstressed position: unstressed /a/ before a palatal nasal appears as $[\mathrm{e}]$ in the target language, while unstressed /e/ before a palatal nasal appears as [i] , as shown in (12). Let us therefore now examine how children produce underlying /a/ and /e/ in unstressed positions.

\section{4. /a/ and /e/ in unstressed position before palatal nasals}

So far, we have focused on how children produce target stressed /a/ and /e/ in different contexts (allophony). However, it is also worth looking at how children treat these vowels in unstressed position in the same contexts. We considered all forms that have an unstressed vowel that in principle could correspond to a word in which the vowel is stressed, such as banho - banheira 'bath' (as in: taking a bath) - 'bath' (physical object). Actual morphologically related pairs are rarely present in our database. Nevertheless, children produce some words with the stressed vowel, and some with the unstressed vowel. The variation in the system between stressed and unstressed occurrences of vowels should thus also be present in the child language data.

\subsubsection{Target unstressed /a/ before nasals in children's productions}

In unstressed position, target underlying /a/ surfaces as $[\mathrm{e}]$ in the target language, and thus also before nasals, as shown in (18). Children, too, produce mostly [e] in this context, as shown in Figure 5. The total numbers of productions of unstressed /a/ before nasals is 300 .

(18) Children's production data of target unstressed /a/ $\rightarrow$ [e]/ Adult form $\mathrm{m}$ [e'm]ocas $\mathrm{b}$ [e'j]eira [em]arelas

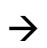

\section{Child's production}

ap[èn]a-lo

$\mathrm{b}[\mathrm{e}$ j] $]$ eira

gaf[e'n]oto

eng[e'n]ar

$\mathrm{b}[\mathrm{e}$ j] $]$ eira

ch['mm]ar $\rightarrow$ [me'ms]

$\rightarrow$ [beire]

$\rightarrow$ [eme'selef]

$\rightarrow$ [pejnalu]

$\rightarrow$ [me'ðrjte]

$\rightarrow$ [gefejnoti]

$\rightarrow$ [ẽgenari]

$\rightarrow$ [be'neje]

$\rightarrow \quad\left[\int e^{\prime} \operatorname{mar}\right]$
(Inês1;5.11)

(Inês 1;9.19)

(Laura 2;2.30)

(Raquel 2;3.3)

(Luís 2;4.4)

(Laura 2;4.30)

(Luís 2;2.27)

(Pedro 2;8.19)

(Pedro 2;9.22) Nasal consonant

'breast' dim
'bath'
'yellow'
'to cath it' $1^{s t} s g$
'bath'
'grasshopper'
'to cheat'
'bath'
'to call'

The fact that children produce unstressed /a/ before a nasal in an adult-like way is perhaps not surprising given the fact that there is no alternation for underlying /a/ before nasals in the target language: in both stressed and unstressed position they 


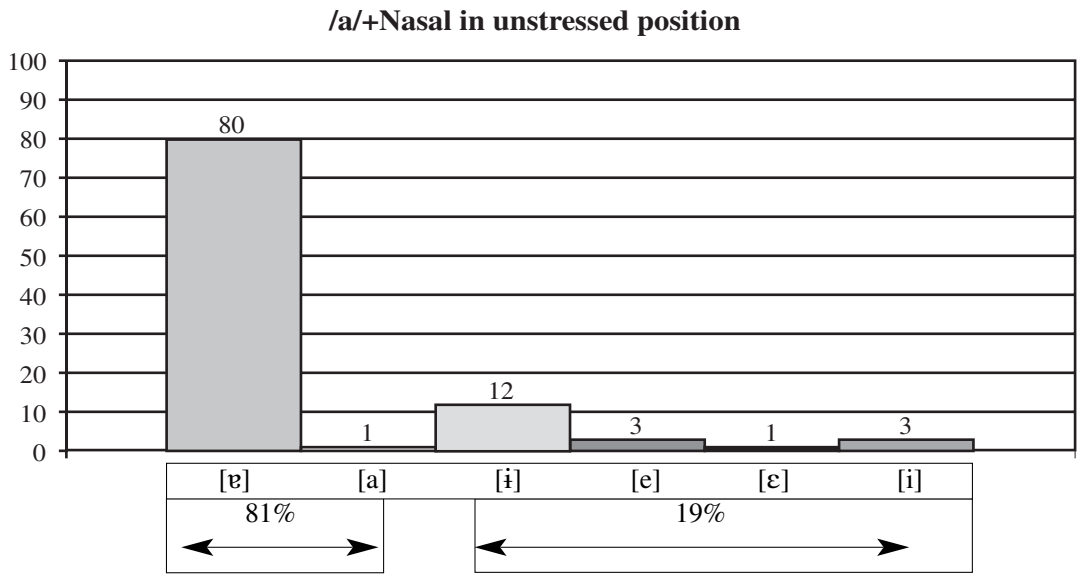

Figure 5. Percentage of different realizations for unstressed /a/ before nasal.

surface as [ $\mathrm{e}]$. Occasionally, unstressed /a/ is realized as [i] by children, as can be seen in Figure 5. We will come back to this in the discussion.

\subsubsection{Target unstressed /e/ in children's productions}

In unstressed position, underlying /e/ before a palatal surfaces as [i] and not as [e] in the target language. Figure 6 presents children's realizations of unstressed /e/

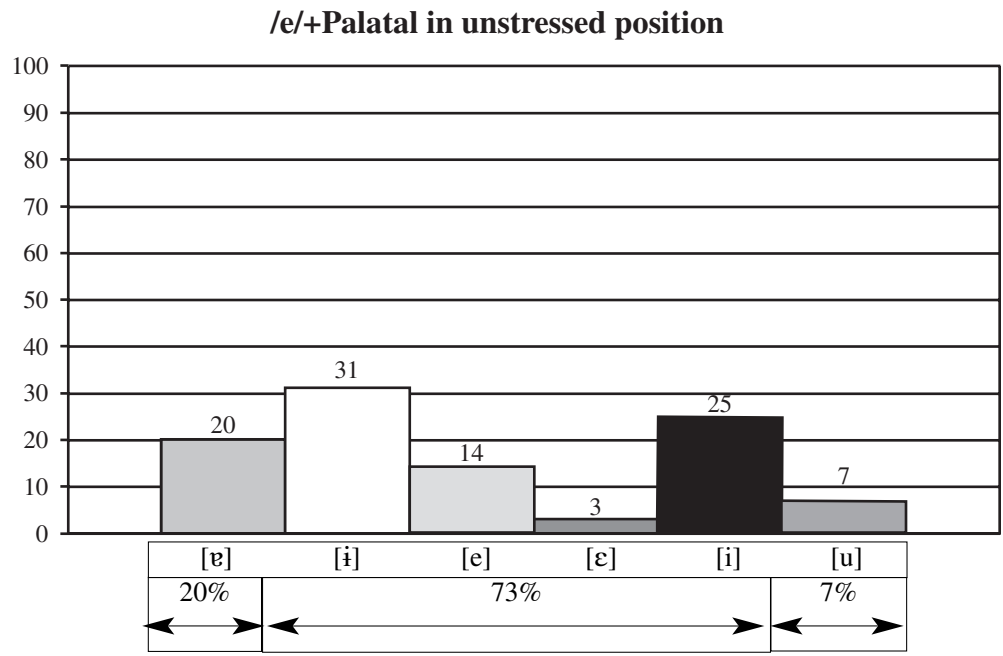

Figure 6. Percentage of different realizations for unstressed /e/ before palatal. 
before palatal consonants. The total number of children's productions of unstressed /e/ before palatals is 403 .

The figure shows a considerable amount of variation, unlike that for underlying /a/ in a nasal context. In (19) examples are provided from children's productions of unstressed underlying /e/ before a palatal consonant (nasal, liquid, fricative), while (20) presents data of an unstressed underlying /e/ before a palatal glide. Here we are dealing with a special case, as the resulting diphthongs do not generally reduce as we saw in (10).

(19) Children's production data of target unstressed /e/ $\rightarrow$ [i] $/$

\begin{tabular}{|c|c|c|c|c|}
\hline \multicolumn{5}{|c|}{$n$} \\
\hline $\mathrm{f}\left[\mathrm{i}^{\prime} \int\right] \mathrm{ou}$ & $\rightarrow$ & [fe' $\mathrm{fo}$ & (Marta $1 ; 11.10)$ & 'to close' $3^{\text {rd }} \mathrm{sg}$ \\
\hline uma $a b\left[\dot{t}^{\prime} \Lambda\right]$ inha & $\rightarrow$ & [umabi'Kine] & (Marta 2;1.19) & 'one bee' \\
\hline f[i'f]ar & $\rightarrow$ & [pi'far] & (Raquel 2;3.3) & 'to close' \\
\hline$a b\left[\dot{i}^{\prime} \Lambda\right]$ inhas & $\rightarrow$ & [ebi'Кine $\left.\int\right]$ & (Laura 2;9.30) & 'bees' \\
\hline $\mathrm{t}[\mathrm{i}]$ 'lhado & $\rightarrow$ & [ti'Kadu]/ [ti'Kadu] & (Laura $3 ; 2.4)$ & 'roof' \\
\hline $\mathrm{t}[\mathrm{i}]$ 'lhado & $\rightarrow$ & [t'Kadu] & (Laura 3;3.10) & 'roof' \\
\hline
\end{tabular}

(20) Children's production data of target unstressed /e/ $\rightarrow$ [e]/ Palatal glide

Adult form

$1[\mathrm{ej}]$ tinho

1[ej] tinho

qu[ej]'jinho

$\mathrm{p}$ [ej]'xinho

$\mathrm{b}[\mathrm{ej}] \mathrm{jinhos}$

$\mathrm{p}$ [ej]'xinhos

d[ej]'tar

d[ej]'tar

$\mathrm{d}[\mathrm{ej}]$ xou

$\mathrm{p}[\mathrm{pj}]$ 'xinhos
Child's production

$\rightarrow$ [titiw]

$\rightarrow$ [titiw]

$\rightarrow$ [ki'Jinu

$\rightarrow$ [pi'zinu]/[pïsinow]

(Inês $1 ; 8.2$ )

(Inês 1;10.29)

(Marta 1;7.18)

$\rightarrow$ [bej'zin $\left.\int\right] /[$ bej'Sini]

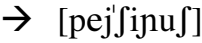

$\rightarrow$ [dejtari]

(Luís 1;9.29)

(Laura 2;4.30)

(Laura 2;8.23)

(Laura 3;1.6)

$\rightarrow$ [ditar]

$\rightarrow\left[\mathrm{de}^{\prime} \mathrm{\int} \mathrm{o}\right]$

(Laura 3;2.4)

(Pedro 3;2.25)

$\rightarrow$ [pej]'in]/[pej'finu $]$ (Pedro 3;6.22) 'milk' dim

'milk' dim

'cheese' dim

'fish' dim

'kiss' dim

'fish' dim

'to go to bed'

'to go to bed'

'to leave'

'fish' dim

From Figure 6, we can conclude that unstressed /e/ before palatal consonants is most often realized as a coronal vowel. It can be realized as either the reduced vowel [i] , the unreduced [e], but also as [i]. However, it is also often realized as [e].

Again, we see that there is much more variation with /e/ before palatal consonants than with /a/ before nasal consonants. Apparently, the latter process is easier to acquire. We will come back to this in the discussion.

\subsection{Summary of the results}

To summarize the results of our investigation we can say that children are able to learn the allophonic variation: In neutral contexts children realize stressed target /a/ invariably as a dorsal vowel [a]. However, before a nasal children usually produce [e], as shown in Figure 3. Only in $11 \%$ of the cases did children realize [a]. For stressed target /e/ vowels, a similar - although less robust pattern - was shown. Whereas stressed 
target /e/ in neutral contexts was invariably realized as a coronal vowel (mostly /e/), in palatal contexts much more variation was seen, as shown in Figure 4. Children produced the vowel target-like as [e] in 56\% of the cases. Thus, even though the percentage correct lies behind the percentage correct for /a/ in a nasal context, the children show evidence that they are in the process of acquiring the allophonic variation in this context. However, there is a difference between the two allophonic contexts. In developmental terms, children start exhibiting $[\mathrm{e}] /[\mathrm{e}]$ vowel alternation for targets with underlying /e/ very early in production, but it takes quite some time before the system has stabilized; on the contrary, targets with underlying /a/ match the target system much earlier. In other words, the phonological process by which stressed /a/ surfaces as $[\mathrm{e}]$ in a nasal environment (see the examples in (7a)) is acquired earlier than the process by which stressed /e/ surfaces as [e] in a palatal environment (7b).

Surprisingly enough, the contrast between /e/ and /a/ is even starting to be acquired in the neutralizing context, i.e. before a palatal nasal, although this process has not been completed. Before a palatal nasal target /a/ is produced target-like [ $\mathrm{e}]$ in $96 \%$ of the cases; in that context target /e/ is produced as [e] 70\%. In the remainder of the cases a coronal is realized, indicating that the children have some knowledge of the underlying coronal nature of the target vowel.

We further considered children's productions of target /a/ before nasals and target /e/ before palatals in unstressed position. For target /a/ children predominantly produced the unstressed target-like variant $[\mathrm{e}](80 \%)$, but sometimes they opted for the default vowel [i] (12\%). For target /e/ children produced a coronal vowel in $73 \%$; in $20 \%$ of the cases they realized a dorsal vowel [e]. The data are summarized in Table 1.

Table 1. Comparison of stressed and unstressed /e/ and /a/.

\begin{tabular}{|c|c|c|}
\hline & /a/ before nasal & percentage \\
\hline \multirow{2}{*}{$\begin{array}{l}\text { Stressed /a/ } \\
(\text { target }[\mathrm{e}])\end{array}$} & {$[\mathrm{e}]$} & 88 \\
\hline & [a] & 11 \\
\hline \multirow{3}{*}{$\begin{array}{l}\text { Unstressed /a/ } \\
\text { (target }[\mathrm{e}])\end{array}$} & [i] & 12 \\
\hline & {$[\mathrm{e}]$} & 80 \\
\hline & /e/ before palatal C & percentage \\
\hline \multirow{3}{*}{$\begin{array}{l}\text { Stressed /e/ } \\
(\text { target }[\mathrm{e}])\end{array}$} & {$[\mathrm{e}]$} & 55 \\
\hline & [e] & 26 \\
\hline & {$[\varepsilon]^{3}$} & 17 \\
\hline \multirow{4}{*}{$\begin{array}{l}\text { Unstressed /e/ } \\
\text { (target [i]]) }\end{array}$} & [i] & 31 \\
\hline & [i] & 25 \\
\hline & {$[\mathrm{e}]$} & 20 \\
\hline & [e] & 14 \\
\hline
\end{tabular}

3. Only the least developed children João and Marta seem to use both [e] and [ $\varepsilon$ ] for stressed target /e/. We hypothesize that these children have not fully acquired the contrast between /e/ and /e/. The same may hold for the contrast between /o/ and /o/ (see Fikkert 2005). 


\section{Discussion}

Children are faced with the following puzzle: stressed $[\mathrm{e}]$ in the context of a palatal nasal can originate from underlying /e/ or /a/. How then do children arrive at the conclusion that the stressed vowels in aranha [e'rene] 'spider' and desenhos [di'zejuf] 'drawings' are underlyingly different? We saw that children produce /a/ before a palatal nasal in $96 \%$ of the cases as dorsal, and /e/ before a palatal nasal in $30 \%$ as a coronal vowel, and in $70 \%$ of the cases as dorsal [e]. In other words, children seem to be treating both vowels differently, at least in part. In case of /a/ the target language always realized a dorsal vowel, both in stressed and in unstressed position. It is therefore not surprising that children realize a dorsal vowel as well. However, the target language realizes an underlying /e/ differently, depending on the position: in neutral contexts and in unstressed position underlying /e/ is realized as coronal. In stressed position before a palatal the target language invariably has dorsal [e]. Yet, children produce stressed underlying /e/ as coronal $30 \%$ of the time. Perhaps the most striking result is that children start to distinguish the contrast between /e/ and /a/ in the neutralizing context, which under all hypotheses would have been the most difficult to acquire. The question is how do they do it? The first hypothesis would of course be that children know the morphologically related words and can use this information to build abstract phonological representations. This is depicted in (21):
a. $\operatorname{ar}[\mathrm{e}] \mathrm{nh}]+\mathrm{a} \quad$ 'spider'


‘spider’ dim
b. $\operatorname{de}[\mathrm{e}[\mathrm{e}] \mathrm{nh}]+\mathrm{os}$ 'drawings' $\operatorname{des}[\mathrm{i}]$ 'nh $]+$ inhos 'drawings' dim

/a/

However, we analyzed the database for the existence of related words in the children's data and these are extremely rare. ${ }^{4}$ Therefore, there is no support for this hypothesis on the basis of production data. Of course, it could be the case that children only produce one form of a pair, but perceive or passively know related pairs, and that the passive lexicon has guided these children. We are not in a position to evaluate this possibility as no perception data, nor analyses of child-directed EP speech are available to us yet.

In general, we also noticed a difference in accuracy of production in the two different allophonic contexts. Although both /a/ before nasals and /e/ before palatals surface as $[\mathrm{e}]$ in the target language, we saw that children produce underlying /a/

4. Unfortunately, we do not have access to a child-directed speech corpus to see whether the lack of morphologically related words is characteristic of child language, or whether it also reflects the input to children. 
much more adult-like than underlying /e/, for which they often produce a coronal vowel. It could be the case that children have noticed that /e/ before palatals in unstressed position usually surfaces as a coronal vowel, and hence, that before palatal nasals coronal vowels can occur. They may generalize that to stressed position. However, this still does not explain why this only happens to stressed underlying /e/ and not to stressed underlying /a/.

Stressed /a/ before a nasal was produced either target-like as [e] (88\%), or as [a], i.e. the underlying vowel. Thus, in this position, the child produces a dorsal, but not always the reduced dorsal. Standard EP does not allow a sequence of a low vowel plus a nasal, nor nasalized low vowels (Mateus \& d'Andrade 2000). The fact that children do sometimes produce this sequence indicates that they have not yet fully acquired this constraint. The children who produced the [a] before a nasal consonant did so only in early stages of development, indicating that this constraint is acquired early.

In unstressed position, underlying /a/ before nasals was produced target-like as [e] $(80 \%)$. It appeared as [i] in $11 \%$ of the cases. /a/ is underlyingly specified as [low] and [dorsal]. Fikkert (2005) proposes that vowel reduction involves the loss of the Tongue Height feature [low] (and the feature [RTR], which is dependent on [low], as shown in (2)). If /a/ loses its feature [low], it results in [e]. If it also loses its Place of Articulation features, we assume that it surfaces as [i]. This implies that children correctly reduce /a/ in unstressed position, but they sometimes reduce the vowel more than necessary. Of interest in this respect is that if children use a filler vowel, they always use [i] (Freitas 2004), which is another indication that [i] is the default vowel, which lacks any active phonological features (see also Dresher 2004).

The behavior of stressed /e/ before palatal consonants shows more variation than stressed /a/ before nasals: Stressed /e/ before palatal consonants is produced target-like as [e] in 55\% of the cases. It is produced as coronal in $43 \%$ of the cases, indicating that children do not apply the 'palatalization' rule, and produce the underlying vowel as [e] or [e]. However, they do not produce [a] showing that they do distinguish underlying /e/ and /a/. Moreover, the fact that both [e] or [ $\varepsilon]$ are produced is an indication for the fact that the Tongue Height dimension of the vowel system is not yet in place. In the case of stressed /e/, there was no clear development: if anything the amount of variation increases, rather than decrease. For most children this pattern remained stable during the whole period of data collection, indicating that this process is difficult to acquire.

Most puzzling is the behavior of unstressed /e/ before palatals. It is produced target-like as [i] in only $31 \%$ of the cases. We assume that /e/ is characterized by the Tongue Height feature [low]. It does not have a Place of Articulation specification, as we assume coronal to be underspecified. Therefore, if /e/ loses the feature [low], this results in the surface vowel [i]. No further reduction (other than complete deletion) can take place. However, there are three other realizations that children produce: [e] (14\%), [i] (25\%), and [e] (20\%). Why do children show so much variation here?

Unstressed /e/ can appear as [e] in child language, in which case all underlying features are realized and no reduction takes place. This only happens at the earli- 
est stages of development, and very quickly disappears as a possibility. Note that unstressed /a/ was hardly ever produced as unreduced [a]. It is interesting in itself that children produce unreduced vowels, as this is not part of their input (see for a similar situation in Dutch and German, respectively Levelt 2002 and Kehoe \& Lleo 2003). Clearly, they must still be figuring out the underlying nature of these vowels, and once the specifications in the vowel system are acquired, reduction becomes an easy process.

Freitas (2004) showed that both underlying /e/ and / $/$ / in unstressed position are produced as either [i] or [i], particularly by the youngest children. This seems to indicate that children have not fully acquired the contrast between the two vowels [i] and [i]. Fikkert (2005) argued that in the target language [i] is specified for [high], whereas [i] does not have any Tongue Height features and that this contrast is acquired late. The feature [high] is phonologically not very active in Portuguese vowels (see Fikkert 2005). This is why Mateus \& d'Andrade (2000) assumed /i/ to be the default (fully underspecified) vowel (but they only considered stressed vowels). Although not frequently, reduced /a/ sometimes also shows up as [i] (see Figure 5).

Unstressed /e/ also shows up as [ $\mathrm{e}]$ fairly frequently. It is unlikely that children change a coronal to a dorsal, as they make very few errors with respect to Place of Articulation. Our hypothesis is that this vowel is not really dorsal, but is the result of a low vowel with an adjacent palatal consonant with the feature [high]. Under pressure of this feature [high] the low vowel cannot remain low. There are two options: either a high coronal vowel [i] is realized, or the vowel becomes [ $\mathrm{e}$ ], to remain different from the target vowel /i/. Both processes appear in child language.

Thus, we argue that also the stressed surface [e]'s in aranha and desenhos are phonologically different: the first one comes from an /a/ losing its Tongue Height feature [low], the second from an /e/ which is palatalized. ${ }^{5}$ That /e/ in a palatal context is more difficult to acquire than $/ \mathrm{a} /$ in a nasal context is probably also due to the fact that the palatal glides in the language behave differently from palatal consonants, as we saw in (19) and (20). Here the question is whether /e/ plus glide is a diphthong or not. If it is not a diphthong, we would have expected that it would show the same behavior as other /e/'s in a palatal context. However, this is not the case, as /e/ plus palatal glide never undergoes reduction in the target system. In other words, they must be real diphthongs in the target language, as diphthongs never reduce (see (10b)). However, children seem to analyze them as underlying /e/ plus palatal glide on a par with other underlying /e/'s in a palatal context as shown in (20). Sometimes they are produced correctly as diphthongs, but reductions also appear.

The fact that the target language produces /ej/ as [ej] in unstressed position may also have affected the number of unstressed [e] productions for /e/ in child

5. Dresher (2004) makes a case of this point: systems that are phonetically similar, may be very different phonologically. One case that he mentions is the Yawelmani vowel system (Archangeli 1984 ) in which [o] can be underlying /o/ or /u/. The only way to know that these vowels are phonologically different is by their behaviour in phonological processes. 
language. All these facts combined seem to suggest that to acquire the rules involving /e/ is much more complicated that to acquire the rules involving /a/. The latter is simply a matter of vowel reduction and acquiring the constraint against a sequence of a low vowel plus a nasal. To acquire the rules involving /e/ children must learn the reduction process (in the allomorphic context), the palatalization process, and they must learn the difference between simple vowels and diphthongs. The difference between the acquisition of /e/ and /a/ in different contexts is reflected both in the developmental pattern (/a/-related processes are acquired before /e/-related processes) and in the amount of variation in children's productions.

\section{Conclusions}

To conclude, children are able to pick up both allophonic and allomorphic variation at an early stage of development. Children even seem to produce the underlying contrast in a neutralizing context to a certain extent, which was beyond expectation of all hypotheses mentioned in the introduction. From the data we can conclude that children use the allomorphic variation in stressed and unstressed stem vowels to determine the nature of underlying vowels.

We showed that children do not produce vowels as they hear them. Rather, they often make 'errors' with respect to the realization of vowels. This is evidence against an exemplar-based approach. These errors do not seem to go in one particular direction; that is, ease of production does not seem to account for the error patterns. Rather, the error patterns suggest that children are in the process of detecting an abstract phonological system. Our data support the claim made long ago by Jakobson \& Halle (1956) and reinstated by Dresher (2004) that children use phonological processes to build up an abstract system of phonological contrasts. Place of Articulation features are produced correctly very early. The Tongue Height features take longer to learn, and particular the role of the feature [high] seems to take its time. In other words, the large amount of allophonic and allomorphic variation cues the acquisition of a system of phonological contrasts. With contrasts established, phonological representations can be fairly abstract.

Children do sometimes produce full vowels for reduced ones, as predicted under the 'little linguist' hypothesis, but not for all vowels. Target /a/ in unstressed position is always produced as a reduced vowel, never as a full vowel. Stressed /e/ in palatal context is often produced as [e], which is not predicted under the 'little linguist' hypothesis: as [e] occurs in stressed position in the input, children were predicted to start with the assumption that $[\mathrm{e}]$ is one of the phonemic stressed vowels of the language.

The learnability account hypothesized correctly that children can learn allophonic variation. This is both true for the variation of the stressed vowels /a/ and /e/, and presumably also for the variation of the nature of the vowel in stressed and unstressed position. As the data do show variation, errors and some development, this acquisition process is not completed in infancy, but continues in the first years of life. Learnability models furthermore predicted that allomorphic variation is acquired late. For Germanic languages it is often argued that allomorphic varia- 
tion is only acquired after age three and is not fully acquired before school age (Zamuner et al., to appear). EP children seem to start much earlier with the acquisition of allomorphic variation, presumably because of the complexity of the vowel system and the many processes in which vowels are involved: stress-related vowel reduction, allophonic variation of /a/ before nasals, allophonic variation of /e/ before palatals, vowel deletion and vowel harmony. Unfortunately, our database of longitudinal spontaneous child language data provided us with insufficient material to arrive at a more fin-grained pattern of development. Future work should either use more dense databases (Lieven et al. 2003), or design experiments to gain more insight.

\section{References}

Albright, Adam \& Bruce Hayes (2003). «Rules vs. analogy in English past tenses: A computational/experimental study». Cognition 90:119-161.

d'Andrade, Ernesto (1977). Aspects de la Phonologie (Générative) du Portugais. Lisbon: INIC, Centro de Linguística da Universidade de Lisboa.

Archangeli, Diana (1984). Underspecification in Yawelmani Phonology and Morphology. MIT, doctoral dissertation.

Bernhardt, Barbara \& Joseph Stemberger (1998). Handbook of Phonological Development: from the Perspective of Constraint-based Non-linear Phonology. San Diego: Academic Press.

Bybee, Joan (2001). Phonology and Language Use. Cambridge: Cambridge University Press.

Dresher, Elan (2004). «On the acquisition of phonological contrasts». In: van Kampen; Baauw (eds.). Proceedings of GALA 2003. Volume 1. Utrecht: LOT, pp. 27-46.

Echols, Catherine H. \& Elisa Newport (1992). «The Role of Stress and Position in Determining First Words». Language Acquisition 2: 189-220.

Fennell, Christopher T. (2004). Infant attention to phonetic detail in word forms: knowledge and familiarity effects. Ph.D. Thesis at the University of British Columbia.

Fikkert, Paula (1994). On the Acquisition of Prosodic Structure. Leiden University, doctoral dissertation. The Hague: Holland Academic Graphics.

- (2005). «From phonetic categories to phonological features specification: Acquiring the European Portuguese vowel system». Lingue e Linguaggio 4(2): 263-280.

- (to appear). «Acquiring phonology». In: P. de Lacy (ed.), Handbook of Phonological Theory. Cambridge: Cambridge University Press.

Freitas, Maria João (1997). Aquisição da Estrutura Silábica do Português Europeu. Univeristy of Lisbon, doctoral dissertation.

- (2004). «The vowel [i] in the acquisition of european Portuguese». In: van Kampen; Baauw (eds.). Proceedings of GALA 2003. Volume 1. Utrecht: LOT, pp. 163-174.

Gerken, LouAnn (1996). «Prosodic structure in young children's language production». Language 72: 683-712.

Gnanadesikan, Amalia (1995). «Markedness and Faithfulness constraints in child phonology». In: Kager; Pater; Zonneveld (eds.). Constraints in Phonological Acquisition. Cambridge: Cambridge University Press, pp. 73-108. 
Hayes, Bruce (2004). «Phonological acquisition in Optimality Theory: The early stages». In: Kager; Pater; Zonneveld (eds.). Constraints in Phonological Acquisition. Cambridge: Cambridge University Press, pp. 158-203.

Ingram, David (1974). «Phonological rules in young children». Journal of Child Language 1: 29-64.

Jakobson, Roman \& Morris Halle (1956). Fundamentals of Language. The Hague: Mouton.

Jusczyk, P. W., Hohne, E. A., and Bauman, A. (1999). «Infants' sensitivity to allophonic cues for word segmentation». Perception and Psychophysics 61: 1465-1476.

Kager, René (1999). Optimality Theory. Cambridge: Cambridge University Press. Kager, René, Joe Pater \& Wim Zonneveld (2004) (eds.). Constraints in Phonological Acquisition. Cambridge: Cambridge University Press.

Kehoe, Margaret \& Conxita Lleó (2003). «A phonological analysis of schwa in German first language acquisition». Canadian Journal of Linguistics 48: 289-327.

Kerkhoff, Annemarie (2004). «Acquisition of voicing alternations». In: van Kampen; Baauw (eds.). Proceedings of GALA 2003. Volume 2. Utrecht: LOT, pp. 269-280.

Kiparsky, Paul \& Lise Menn (1977). «On the acquisition of phonology». In: MacNamara (ed.). Language and Thought. New York: Academic Press, pp. 47-78.

Levelt, Clara C. (1994). On the Acquisition of Place. University of Leiden, doctoral dissertation. The Hague: Holland Academic Graphics.

- (2002). «Schwa-Schma». Talk presented at NET symposium, Nijmegen, March 2002.

Lieven, Elena, Heike Behrens, Jennifer Speares \& Michael Tomasello (2003). «Early syntactic creativity: a usage-based approach». Journal of Child Language 30: 333370.

Macken, Marlys A. (1995). «Phonological acquisition». In Goldsmith (ed.). The Handbook of Phonological Theory. Cambridge MA: Blackwell, pp. 671-696.

Mateus, Maria Helena (1975). Aspectos da Fonologia Portuguesa. Lisbon: Centro de Estudos Filológicos (2 $2^{\text {nd }}$ edn reviewed, Textos de Linguística 6, 1982).

Mateus, Maria Helena \& Ernesto d'Andrade (2000). The Phonology of Portuguese. Oxford: Oxford University Press.

Peperkamp, Sharon \& Emmanuel Dupoux (2002). «Coping with phonological variation in early lexical acquisition». In Lasser (ed.). The Process of Language Acquisition. Berlin: Peter Lang Verlag, pp. 359-385.

Peperkamp, Sharon, Rozenn Le Calvez, Jean-Pierre Nadal \& Emmanuel Dupoux (in press). «The acquisition of allophonic rules: statistical learning with linguistic constraints». To appear in: Cognition.

Smith, Neil (1973). The Acquisition of Phonology: A Case Study. London: Cambridge University Press.

Smolensky, Paul (1996). «On the comprehension/production dilemma in child language». Linguistic Inquiry 27: 720-731.

Swingley, Daniel (2005). «11-month-olds' knowledge of how familiar words sound». Developmental Science, 8, 432-443.

Tesar, Bruce \& Paul Smolensky (1998). «Learnability in Optimality Theory». Linguistic Inquiry 29: 229-268.

- (2000). Learnability in Optimality Theory. Cambridge, MA: The MIT Press. 
Wetzels, Leo (1995). «Mid-vowel alternations in the Brazilian Portuguese verb». Phonology 12: 281-304.

Zamuner, Tania, Annemarie Kerkhoff \& Paula Fikkert (2006). «Acquisition of voicing neutralization and alternations in Dutch». In: Proceedings of the 30th annual Boston University Conference on Language Development. Somerville, MA: Cascadilla Press, pp. 701-712. 